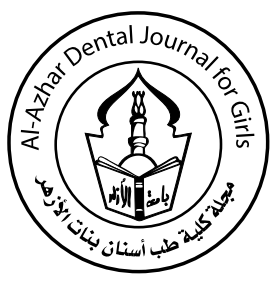

\title{
Fracture Resistance and Retention of Metal-Free Inlay Retained Fixed Partial Dentures
}

\author{
Roqaia M. Al Assar ${ }^{(1)}$, Mohammed A. Al yasky ${ }^{(2)}$, Mona H. Mandour ${ }^{(3)}$ and Rania A. Amin $^{(3)}$
}

Codex : 46/1710

dentaljournal.forgirls@yahoo.com

\begin{abstract}
Statement of the problem: Conservative esthetic restorative dentistry has become an essential component in modern clinical practice. However, the inlay retained fixed partial dentures (IRFPDs) have a higher risk of fracture and dislodgement due to minimal preparations. Purpose: to compare fracture resistance and retention of Lithium disilicate (IPS e.max) and Polyetheretherketone (BioHPP) IRFPDs fabricated with heat-press technique and CAD/CAM system. Materials and Methods: Forty models, each including extracted mandibular $2^{\text {nd }}$ premolar and $2^{\text {nd }}$ molar embedded in an epoxy resin block with $10 \mathrm{~mm}$ intra-abutment distance representing missing mandibular $1^{\text {st }}$ molar were constructed. The premolar and molar of each model received standardized class II inlay preparations. The constructed models were randomly divided into four groups; Group (1): IPS e.max Press IRFPDs, Group (2): IPS e.max CAD IRFPDs, Group (3): BioHPP Granulates IRFPDs, and Group (4): breCAM.BioHPP IRFPDs. All IRFPDs were cemented using RelyX Ultimate adhesive resin cement. Samples were stored for 24 hours in distilled water at $37^{\circ} \mathrm{C}$, and then thermocycled for 5000 cycles. Universal testing machine was used to measure fracture and dislodging loads. Samples were examined for determination of failure mode using a magnifying lens. Results: The statistically significant highest mean dislodging load value was obtained in IPS e.max Press IRFPDs, followed by IPS e.max CAD, with the least value recorded in breCAM.BioHPP. In contrast, breCAM.BioHPP IRFPDs revealed the statistically significant highest mean fracture load value, followed by BioHPP Granulates, while the least mean fracture value was recorded in IPS e.max Press. Most failure occurred in IPS e.max groups was connector fracture, while in BioHPP groups was plastic deformation. Conclusions: Retention and fracture resistance of metal-free inlayretained bridges are significantly affected by both; material type and construction method. BioHPP has significant advantages for dental applications because of higher fracture resistance and better stress distribution. The bond strength at IPS e.max/ resin cement interface is considered a reliable bond presenting better retention to IRFPDs. Being a brittle material, connector fracture is the predominant failure mode of IPS e.max IRFPDs; however, BioHPP has low elastic modulus showing plastic deformation as a predominant failure mode.
\end{abstract}

1. Assistant Lecturer of Crowns \& Bridges, Faculty of Dentistry (Girls Branch), AlAzhar University.

2. Professor of Operative Dentistry, Dean of Faculty of Dentistry, Sinai University.

3. Professor of Crowns and Bridges, Faculty of Dentistry (Girls Branch), AlAzhar University.

4. Associate Professor of Crowns and Bridges, Faculty of Dentistry (Girls Branch), AlAzhar University. 


\section{INTRODUCTION}

In current dental practice, the treatment philosophy is based on the least invasive approach, whereby intact tooth tissues are conserved as much as possible ${ }^{(1)}$. Therefore, if fixed partial denture (FPD) is indicated and enough sound tooth structure is available, it would be desirable to restore a missing tooth with an inlay-retained fixed partial denture (IRFPD) instead of a crownretained FPD to minimize the amount of tooth loss during preparation ${ }^{(2)}$. These treatments have several advantages over conventional bridges, especially in relation to conservation of tooth structure and their reversibility ${ }^{(3)}$.

There are various extensive studies comparing the compatibility of IRFPDs as opposed to crown retained FPDs, to which it states that IRFPDs can be safely used as an alternative ${ }^{(4-7)}$. However, the IRFPDs have a higher risk of dislodgement and fracture due to minimal preparations ${ }^{(8,9)}$. Moreover, there are limited studies on the mechanical strength and retention of these restorations.

Nowadays, monolithic lithium disilicate is considered the material of choice selected by many clinicians for construction of many types of restorations even IRFPDs in the posterior sites provided that appropriate case selection, favorable occlusion and short span length is guranteed ${ }^{(10)}$. The popular widespread diffusion in the daily practice of monolithic lithium disilicate restorations is a result of three main reasons. The first; the possibility of manufacturing low thickness restorations adhesively bonded to the dental substrate (i.e. achieve the minimally invasive approach with excellent adhesion properties and excellent esthetics) ${ }^{(10)}$. The second; being a monolithic restoration, there is a reduction in technical complications like chippings and fractures frequently reported in posterior $\operatorname{areas}^{(11-13)}$. In addition, according to some in vitro studies $^{(14-16)}$, monolithic lithium disilicate crowns and FPDs, either CAD/CAM or heat-pressed, are more resistant to fatigue fracture compared to bilayered, hand veneered ones, showing higher fracture loads comparable to the metal-ceramic restorations. The third; several in-vitro studies (17-19) used lithium disilicate in construction of posterior IRFPDs (i.e. beyond the manufacturer's recommendation) and compared them to zirconia-based IRFDPs. Although the higher load-bearing capacities for zirconia-based IRFDPs, one clinical study reported a high failure rate $(20 \%)$ mainly related to debonding, major chipping of the veneering ceramic, and framework fracture during an observation period of only 12 months ${ }^{(20)}$. It was concluded that a fracture-resistant framework material is not the only factor ensuring clinical success of all-ceramic IRFPDs; but tooth preparation and framework design of IRFPDs seem to be of high relevance ${ }^{(21)}$.

Moreover, the long-term clinical performance of 3-unit, monolithic lithium disilicate FPDs was studied not only for replacement of anterior teeth or premolars (as suggested by the manufacturer) but also for missing molars (beyond the manufacturer's recommendations) ${ }^{(11)}$. After 5 years, the survival and success rates were $100 \%$ and $91.1 \%$ for anterior and posterior FPDs, respectively, and then they were reduced after 10 years to $87.9 \%$ and $69.8 \%$, respectively. Considering that 10 - year survival rates of 87.0 to $89.2 \%$ have been reported for the metal-ceramic FPDs by some systematic reviews ${ }^{(13,22)}$, Kern et al ${ }^{(11)}$ stated that the monolithic lithium disilicate can be regarded as a promising candidate to replace metal-ceramics for short span freestanding bridges. Their mechanical performance is multifactorial, strongly related to shape of the microstructure and size and radius of the connectors among other factors ${ }^{(10,11)}$.

Yamaner et al ${ }^{(23)}$ studied the effect of material type and fabrication technique on fracture resistance of adhesively luted inlay restorations. It was concluded that CAD/CAM-fabricated lithium disilicate ceramic inlays have higher fracture resistance 
values compared to heat-pressed fabricated lithium disilicate ceramic.

BioHPP, a modified polyetheretherketone (PEEK) containing 20\% ceramic fillers has recently been introduced in dentistry ${ }^{(24)}$. In addition to excellent biocompatibility, good wear resistance, good polishing properties, and low plaque affinity; BioHPP has good mechanical properties enabling it to be used as a viable alternative to ceramic restorations ${ }^{(25,26)}$. The major advantage of this material is a 4-GPa modulus of elasticity, making it as elastic as bone, allowing it to act as a stress breaker and reduce the forces transferred to the restoration and the tooth root accordingly ${ }^{(27)}$.

Stawarczy et al (28) studied the influence of different fabrication methods of 3-unit reinforced polyetheretherketone FDPs on fracture load and failure type. It was concluded that milled PEEK FPDs displayed advantages over FPDs pressed from granular PEEK. PEEK reinforced with other inorganic fillers can be potentially used as crown and bridge material. Industrial pre-pressing of blanks (CAD/CAM/ pellet) increases the stability and reliability of PEEK restorations.

With the introduction of different materials with different mechanical, physical and microstructural properties to construct FPD; it was important to experiment constructing posterior IRFPD using these innovative materials and techniques, hoping that this will compose a foundation for a successful prognosis of this type of restoration based on their advantages previously illustrated.

Therefore, the present study included two main materials (lithium disilicate glass ceramic and modified polyetheretherketone); both differ widely in their elastic moduli (95 \pm 5 and 4 GPa respectively) as two alternatives to zirconia based ceramics aiming to reduce common failures recorded with IRFPD. The null hypothesis tested was that material type and construction method have no influence on retention and fracture resistance of IRFPDs.

\section{MATERIALS AND METHODS}

To conduct the present study, 80 freshly extracted human teeth (40 mandibular 2nd premolars and 40 mandibular 2nd molars), were selected in accordance with guidelines from research ethics committee approval of Faculty of Dental Medicine for Girls, Al Azhar University. The teeth were rinsed thoroughly under running water, cleaned and stored in $0.1 \%$ thymol solution.

\section{Models construction}

Forty models ( $\mathrm{N}=40)$, each including a premolar and a molar embedded in an epoxy resin block with $10 \mathrm{~mm}$ intra-abutment distance representing missing mandibular $1^{\text {st }}$ molar were constructed according to the following procedure:

A mandibular $1^{\text {st }}$ molar of $10 \mathrm{~mm}$ mesio-distal width was selected to keep the intra-abutment distance constant among the samples. Putty consistency of Zeta plus (3M ESPE, Seefeld, Germany) was mixed and placed in the premolarmolar region of a prefabricated plastic dental arch (Elbana, Alexandria, Egypt). By the aid of a dental surveyor (Snowdent, Guangdong, China) the teeth were embeded into the impression mix in the plastic dental arch in a parallel position and at the same occlusal level. After rubber base setting, the mandibular $1^{\text {st }}$ molar was removed and its socket was closed by remodeling wax (El-Kods Waxes Co. Egypt). An occlusal index was taken by putty consistency of Zeta plus (3M ESPE, Seefeld, Germany). The mandibular $2^{\text {nd }}$ premolar and $2^{\text {nd }}$ molar were removed from the plastic dental arch and placed into their corresponding positions in the index. A sheet of remodeling wax was wrapped around the borders of the index and sealed with sticky wax (El-Kods Waxes Co. Egypt). After boxing, epoxy resin (East Coast Resin, USA) was mixed following manufacturer's instructions and poured into the index on a vibrator. After epoxy resin setting, the boxing wax was removed and the rubber base index was separated from the epoxy resin model. The procedure was repeated to obtain 40 models $(\mathrm{N}=40)$. 


\section{Teeth preparation:}

The premolar and molar of each model received standardized class II inlay preparations, in accordance with general principles for ceramic inlay restorations ${ }^{(29)}$.

\section{Cavity preparation guidelines:}

Centroid milling machine ( $\mathrm{CNC}$, Milling machine, USA) with two diamond stones selected from the Inlay/Onlay preparation Kit (Zhengzhou Smile Dental Equipment Co, China) was used to perform standardized preparations. The occlusal cavity occupied bucco-lingually $(3 \pm 1 \mathrm{~mm} / 4 \pm 1$ $\mathrm{mm})$ and mesio-distally $(5 \pm 1 \mathrm{~mm} / 7 \pm 1 \mathrm{~mm})$ for the premolar/molar abutments, respectively. The depth was adjusted at $2 \mathrm{~mm}$ measured from central groove. Proximal cavity was extended with flared buccal and lingual walls $(4 \mathrm{~mm} / 5 \mathrm{~mm})$ for the premolar/ molar abutments, respectively. The proximal box was 4 $\mathrm{mm}$ long and $1.5 \mathrm{~mm}$ deep. Occlusal divergence angle was set at $10^{\circ}-12^{\circ}$. Cavosurface margins were finished in butt joints with no bevels. Internal line and point angles were rounded. Prepared dentin was sealed with an adhesive system (Single bond, 3M, ESPE, USA) to prevent contamination.

\section{Samples' Grouping:}

After teeth preparation, the constructed models $(\mathrm{N}=40)$ were randomly divided into four groups according to material type and construction method; Group (1): IPS e.max Press IRFPDs, Group (2): IPS e.max CAD IRFPDs, Group (3): BioHPP Granulates IRFPDs, and Group (4): breCAM.BioHPP IRFPDs.

\section{IRFPDs construction:}

To standardize the constructed IRFPDs among the tested groups; 1-CAD/CAM milled wax patterns were used for construction of pressed IRFPDs. 2-The design used for the construction of $\mathrm{CAD} / \mathrm{CAM}$ wax patterns was followed during the construction of CAD/CAM IRFPDs. 4.a: Construction of IRFPDs using Press technique, Group (1) and Group (3):

\section{Construction of 20 CAD/CAM wax patterns:}

CAD/CAM Roland machine (Roland DG Corporation. Japan), was used for milling twenty IRFPDs wax patterns using CAD/CAM wax discs (Dental CAD/CAM Wax-On White disc, On Dent, Germany), according to the following procedure:

Each constructed model was sprayed with light reflecting powder (Occlutec, Scanspray. Renfert GmBh. USA), and secured on the tray of Smart Optics -3D- Scanner (Activity 850 3D Scanner, Germany), for taking the optical impression. Data were transferred to the computer connected to the milling machine to start designing. The fully anatomical IRFPD design was formed according to the manufacturer's directions and software recommendations including; $30 \mathrm{~mm}$ die spacer, modified ridge-lap pontic and $4 \times 4 \mathrm{~mm}^{2}$ connector dimensions with rounded $0.6 \mathrm{~mm}$ radius of curvature at the gingival area ${ }^{(30,31)}$. Milling of wax patterns was then activated.

\section{4.a.i. Construction of IPS e.max Press IRFPDs, Group (1):}

Ten IPS e.max Press IRFPDs were constructed using the following procedure: 1) Spruing of 10 CAD/CAM wax patterns, 2) Investing using IPS Press Vest investment material (Ivoclar Vivadent, Schaan, Liechtenstein, Germany) according to the manufacturer's instructions, 3) Preheating the investment ring and Alox plunger in the conventional preheating furnace (Apex, USA), 4) Wax elimination, 5) Pressing in EP600 press furnace (Ivoclar, Schaan, Germany), 6) Divesting, finishing and polishing according to manufacturee's instructions, and 7) Examination of IPS e.max Press IRFPDs using magnifying lens (10X, Optics Co, Ltd, Beijing, China) and checking for complete seating on their corresponding models. 


\section{4.a.ii. Construction of BioHPP Granulates IRFPDs, Group (3):}

Ten BioHPP Granulates IRFPDs were constructed by heat-pressing technique using the same procedure used for construction of IPS e.max Press IRFPDs, with the following exceptions; 1) Brevest for 2 press (For2press, Bredent, Germany) was the investment material, and 2) The "for 2 press" unit (For2press, Bredent, Germany) was used for pressing process.

\section{4.b: Construction of IRFPDs using CAD/CAM} system, Group (2) and Group (4):

\section{4.b.i. Construction of IPS e.max CAD IRFPDs, Group (2):}

Ten IPS e.max CAD IRFPDs were constructed from IPS e.max CAD blocks using the same procedure and systems used for scanning, designing and milling of CAM/CAM wax patterns. After milling, the bridges were inserted into the Programat Furnace (P300) (Ivoclar Vivadent, Germany) in which crystallization process took place, according to manufacturer instructions.

\section{4.b.ii. Construction of breCAM.BioHPP IRFPDs, Group (4):}

Ten BioHPP IRFPDs were constructed from breCAM.BioHPP blanks using the same procedures and systems used for scanning, designing and milling of CAM/CAM wax patterns and IPS e.max CAD IRFPDs.

\subsection{Cementation of IRFPDs:}

All samples were cemented using RelyX Ultimate resin cement after surface conditioning of tooth structure and intaglio surfaces of constructed IRFPDs, in accordance with their respective manufacturers' instructions.

Surface treatment of tooth structure by etching for 15 seconds with Blue Etch $36 \%$ phosphoric acid, StalowaWola, Polska) then rinsing, drying, and bonding (Single Bond, 3M, ESPE, Germany). Conditioning of IPS e.max IRFPD cementation surfaces by etching for 20 seconds using IPS Ceramic Etching Gel (5\% HF acid, Ivoclar Vivadent, Liechtenstein) then washing, drying, and bonding (Single Bond adhesive, 3M, ESPE, Germany). For BioHPP IRFPDs, the cementation surfaces of inlay retainers were abraded with aluminium oxide (110 $\mu \mathrm{m}$, Bredent, Senden, Germany), then cleaned with distilled water in an ultrasonic unit (Bredent, Senden, Germany) and gently air dried. A layer of Single Bond adhesive was applied and allowed to react for 20 seconds.

After cementation, samples were stored for 24 hours in distilled water at $37^{\circ} \mathrm{C}$, then thermocycled in automatic thermal cycling machine (Ropota, automated thermo- cycling, Turkey) for 5000 cycles in two water baths at 5 and $55^{\circ} \mathrm{C}$.

\subsection{Testing Procedures:}

First: Retention test: Half number of samples in each subgroup $(n=5, N=20)$ was subjected to retention test using universal testing machine (Model LRX-plus; Lloyd Instruments Ltd., UK) with a loadcell of $5 \mathrm{kN}$. Data were recorded using computer software (Instron ${ }^{\circledR}$ Bluehill Lite Software). The bridge was suspended from the upper movable compartment of the machine by double orthodonic wire loop engaging the mesial and the distal connectors. A tensile load with pull out mode of force was applied until total dislodgment of the bridge.

Second: Fracture resistance test: The other half number of samples in each subgroup $(n=5, N=20)$ was subjected to fracture resistance test by applying a compressive mode of load at the pontic ${ }^{(14)}$ using a metallic rod with round-tip (5.8 $\mathrm{mm}$ diameter) attached to the upper movable compartment of the testing machine traveling at cross-head speed of $1 \mathrm{~mm} / \mathrm{min}$. with $0.5 \mathrm{~mm}$-thick tin foil sheet inbetween to achieve homogenous stress distribution and minimize the transmission of local force peaks. 


\section{Failure mode assessment}

The fractured samples were examined for determination of failure mode using a magnifying lens (10X, Optics Co, Ltd, China). The failure mode was assessed based on previous publication ${ }^{(32)}$, as follows; Type (1): Connector fracture, Type (2): inlay retainer fracture, Type (3): Plastic deformation of bridge without fracture, Type (4): Fracture of abutment tooth/teeth including cracks and/or cusp fractures, Type (5): Severe fractures of abutment tooth/ teeth that extend beneath the CEJ, and Type (6): Combined failure in bridge and abutment tooth/teeth.

\section{Statistical analysis}

Data was presented as means \pm standard deviations. Unpaired $t$ test was used to compare both materials using the same construction method, as well as to compare both construction methods using the same material. One way analysis of variance (ANOVA) test was used to compare all subgroups. This was followed by Tukey's post hoc test when ANOVA revealed a significant difference.

\section{RESULTS}

\section{$1^{\text {st}}$; Statistical analysis of dislodging load values:}

\section{A- Effect of material:}

Higher mean dislodging load values (N) were recorded in IPS e.max groups, namely; IPS e.max Press (Group1) and IPS e.max CAD (Group 2) compared to BioHPP groups, namely; BioHPP Granulates (Group 3) and breCAM. BioHPP (Group 4), with a statistically significant difference $(\mathrm{p}<0.0001)$ in both Press and CAD/CAM constructed groups. Table (1)

\section{B- Effect of construction method:}

Higher mean dislodging load values $(\mathrm{N})$ were recorded in Press constructed groups, namely; IPS e.max Press (Group 1) and BioHPP Granulates (Group 3) compared to CAD/CAM constructed groups, namely; IPS e.max CAD (Group 2) and breCAM.BioHPP (Group 4), respectively, with a statistically significant difference between the groups in both materials $(\mathrm{p}<0.0001)$. Table (2)

\section{C-Effect of both variables:}

Comparing all groups together revealed that the highest mean dislodging load value was obtained in IPS e.max Press (Group 1), followed by IPS e.max CAD (Group 2), with the least value recorded in breCAM.BioHPP (Group 4). ANOVA test revealed that the difference between groups was statistically significant $(\mathrm{P}<0.0001)$. Table (3)

\section{$2^{\text {nd }}$; Statistical analysis of fracture load values:}

\section{A- Effect of material:}

Higher mean fracture load values $(\mathrm{N})$ were recorded in BioHPP groups, namely; BioHPP Granulates (Group 3) and breCAM.BioHPP (Group 4) compared to IPS e.max groups, namely; IPS e.max Press (Group 1) and IPS e.max CAD (Group 2), with a statistically significant difference $(\mathrm{p}<0.0001)$ in both Press and CAD/CAM constructed groups. Table (4)

\section{B- Effect of construction method:}

Higher mean fracture load values $(\mathrm{N})$ were recorded in $\mathrm{CAD} / \mathrm{CAM}$ constructed groups, namely; IPS e.max CAD (Group 2) and breCAM. BioHPP (Group 4) compared to Press constructed groups, namely; IPS e.max Press (Group 1) and BioHPP Granulates (Group 3), respectively, with no significant difference between IPS e.max groups $(1 \& 2)(\mathrm{p}=0.1891)$, and a statistically significant difference between BioHPP groups (3\&4) $(\mathrm{p}=0.049)$. Table (5)

\section{C-Effect of both variables}

Comparing all groups together revealed that the highest mean fracture load value was obtained in breCAM.BioHPP (Group 4), followed by BioHPP Granulates (Group 3), while the least mean value was recorded in IPS e.max Press (Group 1). ANOVA test revealed that the difference was statistically significant $(\mathrm{P}<0.0001)$. Table (6) 


\section{$3^{\text {rd }}$; Mode of failure analysis:}

The most common failure mode occurred in IPS e.max groups (1 and 2) was connector fracture (i.e. Type 1 mode of failure), while in BioHPP groups (3 and 4), plastic deformation (i.e. Type 3 ) was the predominant failure mode. Table (7)

Table (1): Mean dislodging load $\pm S D(N)$ and comparison of different materials using the same construction method (unpaired test).

\begin{tabular}{|l|c|c|c|}
\hline \multicolumn{1}{|c|}{ Groups } & $\begin{array}{c}\text { Mean dislodging } \\
\text { load } \pm \text { SD }(\mathbf{N})\end{array}$ & t value & P value \\
\cline { 1 - 2 } (1) IPS e.max Press & $275.8497 \pm 35.76$ & \multirow{2}{*}{7.4837} & $<0.0001^{*}$ \\
\cline { 1 - 2 } (3) BioHPP Granulates & $182.7167 \pm 16.43$ & & \\
\cline { 1 - 2 } (2) IPS e.max CAD & $238.3544 \pm 40.32$ & \multirow{2}{*}{7.3240} & $<0.0001^{*}$ \\
\cline { 1 - 2 } (4) breCAM.BioHPP & $140.5104 \pm 12.61$ & & \\
\hline
\end{tabular}

Significance level $P<0.05$, * significant

Table (2): Mean dislodging load $\pm S D(N)$ and comparison of different construction methods (unpaired test).

\begin{tabular}{|c|c|c|c|}
\hline Groups & $\begin{array}{l}\text { Mean dislodging } \\
\text { load } \pm \text { SD }(N)\end{array}$ & $t$ value & Pvalue \\
\hline (1) IPS e.max Press & $275.8497 \pm 35.76$ & \multirow{2}{*}{2.2001} & \multirow{2}{*}{$0.0411^{*}$} \\
\hline (2) IPS e.max CAD & $238.3544 \pm 40.32$ & & \\
\hline (3) BioHPP Granulates & $182.7167 \pm 16.43$ & \multirow{2}{*}{6.4442} & \multirow{2}{*}{$<0.0001^{*}$} \\
\hline (4) breCAM.BioHPP & $140.5104 \pm 12.61$ & & \\
\hline
\end{tabular}

Significance level $P<0.05$, *significant

Table (3): Mean dislodging load $\pm S D(N)$ and comparison of different materials and construction methods (ANOVA test).

\begin{tabular}{|l|c|l|l|}
\hline \multicolumn{1}{|c|}{ Groups } & $\begin{array}{c}\text { Mean dislodging } \\
\text { load } \pm \text { SD }(\mathbf{N})\end{array}$ & F value & P value \\
\cline { 1 - 2 } (1) IPS e.max Press & $275.8497 \mathrm{a} \pm 35.76$ & & \\
\cline { 1 - 2 } (2) IPS e.max CAD & $238.3544 \mathrm{~b} \pm 40.32$ & \multirow{2}{*}{42.845} & $<0.0001^{*}$ \\
\cline { 1 - 2 } (3) BioHPP Granulates & $182.7167 \mathrm{c} \pm 16.43$ & & \\
\cline { 1 - 2 } (4) breCAM.BioHPP & $140.5104 \mathrm{~d} \pm 12.61$ & & \\
\hline
\end{tabular}

Significance level $P<0.05$, *significant

Tukey's post hoc test: means with different superscript letters are significantly different.
Table (4): Mean fracture load $\pm S D(N)$ and comparison of different materials using the same construction method (unpaired test).

\begin{tabular}{|l|c|c|c|}
\hline \multicolumn{1}{|c|}{ Groups } & $\begin{array}{c}\text { Mean fracture } \\
\text { load } \pm \text { SD }(\mathbf{N})\end{array}$ & t value & P value \\
\cline { 1 - 2 } (1) IPS e.max Press & $476.8712 \pm 48.42$ & \multirow{2}{*}{3.9103} & \multirow{2}{*}{$0.001^{*}$} \\
\hline (3) BioHPP Granulates & $600.563 \pm 87.53$ & \multirow{2}{*}{5.0542} & \multirow{2}{*}{$<0.0001^{*}$} \\
\cline { 1 - 2 } (2) IPS e.max CAD & $510.3544 \pm 60.61$ & & \\
\cline { 1 - 2 } (4) breCAM.BioHPP & $684.693 \pm 90.69$ &
\end{tabular}

Significance level $P<0.05$, *significant

Table (5): Mean fracture load $\pm S D(N)$ and comparison of different construction methods (unpaired test).

\begin{tabular}{|l|c|c|c|}
\hline \multicolumn{1}{|c|}{ Groups } & $\begin{array}{c}\text { Mean fracture } \\
\text { load } \pm \text { SD }(\mathbf{N})\end{array}$ & \multirow{2}{*}{ t value } & \multirow{2}{*}{ P value } \\
\cline { 1 - 2 } (1) IPS e.max Press & $476.8712 \pm 48.42$ & \multirow{2}{*}{1.3649} & \multirow{2}{*}{$0.1891 \mathrm{~ns}$} \\
\cline { 1 - 2 } (2) IPS e.max CAD & $510.3544 \pm 60.61$ & \multirow{2}{*}{2.1108} & \multirow{2}{*}{$0.049^{*}$} \\
\cline { 1 - 2 } (3) BioHPP Granulates & $600.563 \pm 87.53$ & & \\
\cline { 1 - 2 } (4) breCAM.BioHPP & $684.693 \pm 90.69$ & &
\end{tabular}

Significance level $P<0.05$, *significant

Table (6): Mean fracture load $\pm S D(N)$ and comparison of different materials and construction methods (ANOVA test).

\begin{tabular}{|l|c|c|c|}
\hline \multicolumn{1}{|c|}{ Groups } & $\begin{array}{c}\text { Mean fracture } \\
\text { load } \pm \text { SD }(\mathbf{N})\end{array}$ & F value & P value \\
\cline { 1 - 2 } (1) IPS e.max Press & $476.8712 \mathrm{c} \pm 48.42$ & & \\
\cline { 1 - 2 } (2) IPS e.max CAD & $510.3544 \mathrm{c} \pm 60.61$ & \multirow{2}{*}{16.014} & $<0.0001^{*}$ \\
\cline { 1 - 2 } (3) BioHPP Granulates & $600.563 \mathrm{~b} \pm 87.53$ & & \\
\cline { 1 - 2 } (4) breCAM.BioHPP & $684.693 \mathrm{a} \pm 90.69$ & & \\
\hline
\end{tabular}

Significance level $P<0.05$, *significant

Tukey's post hoc test: means with different superscript letters are significantly different.

Table (7): Failure mode assessment using magnifying lens after fracture resistance test.

\begin{tabular}{|l|c|c|c|c|c|c|}
\hline \multirow{2}{*}{ Groups } & \multicolumn{6}{|c|}{ Mode of Failure } \\
\cline { 2 - 8 } & Type 1 & Type 2 & Type 3 & Type 4 & Type 5 & Type 6 \\
\hline (1) IPS e.max Press & 3 & 0 & 0 & 1 & 0 & 1 \\
\hline (2) IPS e.max CAD & 4 & 1 & 0 & 0 & 0 & 0 \\
\hline (3) BioHPP Granulates & 0 & 0 & 4 & 0 & 1 & 0 \\
\hline (4) breCAM.BioHPP & 0 & 0 & 3 & 1 & 1 & 0 \\
\hline
\end{tabular}




\section{DISCUSSION}

Although the concept of IRFPD is not new, the general opinion about the prognosis and functionality of such restoration is far from being clear ${ }^{(33)}$ and this had limited its use to highly selective cases making clinicians reluctant in presenting IRFPDs as a restorative option for their patients. However; careful case selection, design preparation, and treatment planning can improve the clinical success of IRFPD. Moreover, with the fast expanding field of esthetic restorative materials and techniques; the prognosis of the conservative IRFPD could be improved.

A growing demand is rising for selection of zirconia-based ceramics that have fracture strength high enough to withstand posterior physiologic loads ${ }^{(34)}$. However, zirconia still presents a challenge in bonding, in addition to delamination and microcracks of the veneering ceramic material are the most long-term failures observed and reported ${ }^{(20,35)}$. Marginal discrepancies and marginal gaps of the CAD/CAM zirconia frameworks are frequently recorded ${ }^{(34,36)}$. Moreover, CAD/CAM zirconia framework requires 6 to 8 hours for sintering and often discourages the delivery of the restoration within the same visit ${ }^{\left({ }^{37}\right)}$. Besides wear of opposing enamel and lack of translucency ${ }^{(34)}$, zirconia with an elastic modulus of $210 \mathrm{GPa}$ would not be considered the absolute best choice for IRFPD construction, although the fact that there is no material can fulfill the whole criteria of success. Moreover, low temperature degradation (LTD), or "aging", of zirconia causing detrimental changes in the mechanical behavior, and exposing zirconia frameworks to the risk of spontaneous catastrophic failure ${ }^{(34)}$.

For proper selection of IRFPD's material, it is necessary to know to what extent this material can resist dislodging forces without debonding and withstand masticatory forces without fracture, thus both forces had to be studied.
To conduct the present study, forty IRFPDs $(\mathrm{N}=40, \mathrm{n}=10)$ were fabricated in accordance with their manufacturers' instructions. For heat-press constructed IRFPDs, CAD/CAM wax patterns were designed and milled then used to achieve standardization with CAD/CAM IRFPDs.

In the present study, full-contoured (monolithic) IRFPDs were designed to exclude the risk of veneering material fracture and/or chipping during testing procedures. The connector dimensions were $4 \times 4 \mathrm{~mm}^{2}$ with rounded broader radius of curvature $(0.6 \mathrm{~mm})$ at the gingival area to enhance fracture resistance of the restoration according to multiple studies ${ }^{(30,31,38)}$.

The statistically significant highest mean dislodging load value was recorded in IPS e.max Press IRFPDs, followed by IPS e.max CAD, with the significantly least mean value recorded in breCAM.BioHPP, table (3). Therefore, the null hypothesis was rejected.

Regarding the material type, table (1), the significantly higher dislodging load values recorded for IPS e.max groups (1 and 2) compared to BioHPP groups ( 3 and 4 ) could be attributed to the different pre-cementation conditioning protocols of each material and the mechanism of bonding at restoration/cement interface ${ }^{(39)}$. In the present study two surface conditioning protocols were followed as recommended by the respective manufacturers. The difference in bond strength could be explained on the basis of the surface morphology created by surface conditioning ${ }^{(39)}$. In Huang et $\mathrm{al}^{(40)}$ study using SEM; the lithium disilicate surfaces etched by HF acid were shown to be more irregular and significantly rougher than the samples conditioned with sandblasting. HF acid can attack the glass phase of ceramics, partially dissolving it and creating microporous retention by exposing areas of lithium disilicate crystals that make up the crystalline phase $^{(41)}$. The increased surface roughness is likely to have contributed to the micromechanical retention between the adhesive and the ceramic ${ }^{(42)}$. 
Several studies demonstrated superior bond strength of lithium disilicate to resin cements after HF conditioning ${ }^{(40-42)}$.

Additionally, IPS e.max has a higher elastic modulus $(95 \pm 5 \mathrm{GPa})$ and according to Braga et $\mathrm{al}^{(43)}$; the higher elastic modulus, the higher bond strength. Moreover; due to the lower thermal expansion of IPS e.max (10.5 x 10-6 K-1) compared to BioHPP (194 x 10-6 K-1), IPS e.max has higher thermal shock resistance ${ }^{(4)}$. The higher the thermal shock resistance of the restoration, the less bond deterioration at restoration/ cement interface during thermocycling ${ }^{(45)}$, hence the more stable bond strength and vice versa.

Regarding the construction method, table (2), a significantly higher dislodging load was recorded in samples constructed using Press technique; IPS e.max Press and BioHPP Granulates (Groups 1 and 3) compared to $\mathrm{CAD} / \mathrm{CAM}$ constructed samples, IPS e.max CAD and breCAM.BioHPP (Groups 2 and 4).

Prochnow et al ${ }^{(46)}$ reported that ceramic etching is a dynamic process, and its impact is dependent on the substrate constitution, substrate surface topography, in addition to acid concentration, and etching period. Hence, pre-pressed industrially manufactured blocks of e.max CAD and BioHPP resisted surface conditioning by $\mathrm{HF}$ acid and sandblasting respectively, more than pressed materials.

In general, retention is known to be influenced by different parameters: the abutment size and surface roughness, cement type, cementation technique, preparation design and degree of divergence ${ }^{(47,48)}$. The exact degree of ideal divergence for the walls has been a subject of debate ${ }^{(48)}$. The contribution of these factors makes comparison between results of different studies difficult.

The fracture resistance test indicates the force (in Newtons) at which the sample fails. In the present study, values from 476 to $684 \mathrm{~N}$ were recorded for all tested groups, table (6). Different testing methods and the difficulty in measuring masticatory forces resulted in a wide range of force values. Saridag et $\mathrm{al}^{\left({ }^{(30)}\right.}$ reported that the highest bite force is found in the first molar region and the posterior FPDs should be strong enough to withstand a load of $500 \mathrm{~N}$.

Assuming maximum mastication forces of about $500 \mathrm{~N}^{(30)}$ in posterior areas, the breCAM.BioHPP and BioHPP Granulates IRFPDs (Groups 3 and 4) represented adequate safety margins. Results of IPS e.max CAD (Group 2) were critical recording a mean value of 510 N. While, IPS e.max Press (Group 1) showed a lower fracture force than 500 $\mathrm{N}(476 \mathrm{~N})$ suggesting that it is unable to withstand extreme occlusal forces in the posterior region.

On the other hand, some authors reported stress applied on a restoration during mastication may range between 441-981 N, 245-491 N, 147-368 $\mathrm{N}$, and $98-270 \mathrm{~N}$ in the molar, premolar, canine, and incisor regions, respectively ${ }^{(49,50)}$. Therefore, according to these values, it is advisable to use BioHPP and IPS e.max anywhere in the oral cavity away from molar region. In any case, the results of the present study were considerably lower if compared to those ranges of molars. This could be attributed to the following three reasons. First, the difference in the inter-abutment distances which affects fracture load ${ }^{(51)}$. The inter-abutment distance varied between 7 and $15 \mathrm{~mm}$ in different studies ${ }^{(17,30,51,52)}$. It was reported that the fracture resistance of IRFPD was reduced by about $25 \%-$ $35 \%$ when the inter-abutment distance was increased from 7 to $11 \mathrm{~mm}^{(51)}$. Second, the difference in pontic forms and cusp morphology may also affect the fracture strength ${ }^{(49)}$. Third, masticatory forces are not only axial, as applied in such test methods. Thus; a direct comparison between in-vivo and invitro chewing force measurement is difficult ${ }^{(1)}$.

In the present study, the breCAM.BioHPP IRFPDs revealed the significantly highest mean fracture load value, followed by BioHPP Granulates, with the significant least value recorded in IPS e.max Press, table (6). Therefore, the null hypothesis was rejected. 
Regarding the material type, table (4), BioHPP IRFPDs (Groups 3 and 4) showed statistically significant higher fracture load than IPS e.max IRFPDs (Groups 1 and 2). Both materials showed extremely different behavior under fracture load as a result of their different elastic modulus. The low elastic modulus of BioHPP resulted in fewer stresses in the corresponding inlay retainers. Thus, during load application, the BioHPP IRFPDs demonstrated higher resilience with more absorption of load, which consequently increased the fracture resistance ${ }^{(50,53)}$. On the other hand, the relatively low fracture resistance results of IPS e.max IRFPDs can be attributed to the brittleness of the material.

These findings were confirmed by Brunton et $\mathrm{al}^{(53)}$ and Vallittu et al ${ }^{(50)}$ who concluded that flexible restorative materials are preferable to ceramic materials because of their resiliency, repairable properties and equivalent fracture resistance.

Due to its intrinsic brittle behavior, lithium disilicate ceramics suffer from fatigue failure during load application ${ }^{(10)}$. That is why the predominant failure mode recorded in IPS e.max IRFPDs was Type 1 (i.e. connector fracture). On the other hand, BioHPP material has higher bending tendencies compared to the more brittle ceramic materials due to the low elastic modulus ${ }^{(54)}$. Therefore, BioHPP IRFPDs showed plastic deformation rather than fracture ${ }^{(50)}$. That is why the predominant failure mode of BioHPP IRFPDs was Type 3 (i.e. plastic deformation). Table(7)

Regarding the construction method, table (5), a higher fracture load was recorded in CAD/CAM constructed IRFPDs compared to Press constructed ones. In IPS e.max groups; IPS e.max CAD showed higher fracture load compared to IPS e.max Press. The reliability of industrially prefabricated ceramic blocks appears to be more consistent than laboratory manually processed ceramics ${ }^{(55)}$. According to Quinn ${ }^{(56)}$, fractures in brittle materials, such as ceramics, initiate from pre-existing defects on the surface or within the bulk of the ceramic material, and propagate under excessive tensile stress. However, the statistical difference was insignificant.

In BioHPP groups, breCAM.BioHPP showed a significant higher fracture load compared to BioHPP Granulates. BioHPP Granulates is the raw material being extruded into BioHPP pellets and breCAM. BioHPPblanks.After the industrial manufacturing of BioHPP, the pellets, in contrast to breCAM.BioHPP blanks, are heated in an oven to be pressed into their final forms. Due to the modified amorphous and crystalline ratio, material properties can be greatly influenced ${ }^{(45)}$, explaining the significant difference between the two subgroups.

These findings were confirmed by Yamaner et $\mathrm{al}^{(23)}$ who stated that the higher fracture force of CAD/CAM restorations may be the result of optimized industrial manufacturing conditions and subsequent minimal voids and volume defects.

The limitation of the present study is that no mechanical loading was applied as part of artificial aging process, which would have provided insight into its negative effects on studied properties. Nevertheless, manufacturer suggested the use of IPS e.max Press and IPS e.max CAD to remain limited to the anterior and premolar regions. Several in-vitro studies used lithium disilicate glass ceramic for construction of posterior IRFPDs and full coverage FPD ${ }^{(30,57,58)}$. Since the aim of the present study was to compare the effects of different materials and construction methods rather than to assess the clinical performance, providing standard conditions for all test materials would be enough for evaluation. Thus, the inherent limitations in this study should be considered particularly because posterior lithium disilicate IRFPDs cannot be recommended for clinical application.

\section{CONCLUSIONS}

Within the limitations of the present study, the following could be concluded: 1) Retention and fracture resistance of metal-free inlay-retained bridges are affected by both; material type and 
construction method. 2) BioHPP has significant advantages for dental applications because of higher fracture resistance and better stress distribution. 3) The bond strength at IPS e.max/ resin cement interface is considered a reliable bond presenting better retention to IRFPDs. 4) Being a brittle material, connector fracture is the predominant failure mode of IPS e.max IRFPDs; however, BioHPP has low elastic modulus showing plastic deformation as a predominant failure mode.

\section{REFERENCES}

1. Kumbuloglu O, Ozcan M, User A. Fracture strength of direct surface-retained fixed partial dentures: Effect of fiber reinforcement versus the use of particulate filler composites only. Dent Mater J 2008;27:195-202.

2. Heumen CC, Kreulen CM, Creugers NH. Clinical studies of fiber-reinforced resin-bonded fixed partial dentures: a systematic review. Eur J Oral Sci 2009;117:1-6.

3. Lutz F and Göhring TN. Fiber-reinforced inlay fixed partial dentures: maximum preservation of dental hard tissue. J Esthet Dent 2000;3:164-71.

4. Meyer Jr A, Cardoso LC, Araujo E, Baratieri LN. Ceramic inlays and onlays: clinical procedures for predictable results. J Esthet Rest Dent 2003;15:338-52.

5. Iglesia-puig Miguel A, Arellano-Cabornero A. Inlay fixed partial denture as a conservative approach for restoring posterior missing teeth: a clinical report. J Prosthet Dent 2003;89:443-5.

6. Thompson MC, Thompson KM, Swain M. The allceramic, inlay supported fixed partial denture. Part 2. Fixed partial denture design: a finite element analysis. Aust Dent J 2011;56:302-11.

7. Christian WP and Kalk W. A systematic review of ceramic inlays in posterior teeth: an update. Int $\mathrm{J}$ Prosthodont 2011;24:566-75.

8. Richard T. A transformation-toughened polycrystalline ceramic posterior inlay/onlay fixed partial denture. Inside Dent 2008;4(5):108-11.

9. Çotert HS and Özturk B. Posterior bridges retained by resin-bonded cast metal inlay retainers: a report of 60 cases followed for 6 years. J Oral Rehab 1997;24(9):697-704.

10. Zarone F, Ferrari M, Mangano FG, Leone R, Sorrentino R. Digitally Oriented Materials: Focus on Lithium Disilicate Ceramics. Int J Dent 2016;1-10.
11. Kern M, Sasse M, Wolfart S. Ten-year outcome of three unit fixed dental prostheses made from monolithic lithium disilicate ceramic. J Am Dent Asso 2012;143(3):234-40.

12. Guichet D. Digitally enhanced dentistry: the power of digital design. J California Dent Asso 2015;43(3):135-41.

13. Sailer I, Makarov NA, Thoma DS, Zwahlen M, Pjetursson BE. All-ceramic or metal-ceramic tooth-supported fixed dental prostheses? A systematic review of the survival and complication rates, Part I: single crowns. Dent Mater 2015;31(6):603-23.

14. Schultheis S, Strub JR, Gerds TA, Guess PC. Monolithic and bi-layer CAD/CAM lithium-disilicate versus metalceramic fixed dental prostheses: Comparison of fracture loads and failure modes after fatigue. Clin Oral Invest 2013;17:1407-13.

15. Guess PC, Zavanelli RA, Silva NR, Bonfante EA, Coehlo $\mathrm{P}$, Thompson VP. Monolithic CAD/CAM lithium disilicate versus veneered Y-TZP crowns: comparison of failure modes and reliability after fatigue. Int J Prosthodont 2010; 23:434-42.

16. Zhao K, Pan Y, Guess PC, Zhang XP, Swain MV. Influence of veneer application on fracture behavior of lithiumdisilicate-based ceramic crowns. Dent Mater 2012;28(6): 653-60

17. Mehmet A, Kilicarslan P, Kedici S. In vitro fracture resistance of posterior metal ceramic and all-ceramic inlay-retained resin-bonded partial dentures. J Prosthet Dent 2004;92:365-70.

18. Wolfarta S. Fracture strength of all-ceramic posterior inlay-retained fixed partial dentures. J Dent Mater 2007; 23(12):1513-20.

19. Mohsen Ch. Fracture resistance of three ceramic inlayretained fixed partial denture designs. An in vitro comparative study. J Prosthet Dent 2010;19(7):531-5.

20. Ohlmann B, Rammelsberg P, Schmitter M, Schwarz $S$, Gabbert O. All-ceramic inlay-retained fixed partial dentures: preliminary results from a clinical study. J Dent 2008;36(9):692-6.

21. Aboushelib MN, Feilzer AJ, Kleverlaan CJ, Salameh Z. Partial-retainer design considerations for zirconia restorations. Quintessence Int 2010;41:41-8.

22. Pjetursson BE, Tan WC, Tan K, Brägger U, Zwahlen M, Lang NP. A systematic review of the survival and complication rates of resin-bonded bridges after an observation period of at least 5 years. Clin Oral Imp Res 2008;19:131-41 
23. Yamaner I, Sertgöz A, Akalın T, Özcan M. Effect of material and fabrication technique on marginal fit and fracture resistance of adhesively luted inlays made of CAD/CAM ceramics and hybrid materials. J Adhes Sci Tech 2017;31(1):1-16.

24. Zoidis P, Bakiri E, Polyzois G. Using modified polyetheretherketone (PEEK) as an alternative material for endocrown restorations. J Prosthet Dent 2017;117:335-9.

25. Schmidlin PR, Stawarczyk B, Wieland M, Attin T, Hammerle CHF, Fischer J. Effect of different surface pretreatments and luting materials on shear bond strength to PEEK. Dent Mater 2010;26:553-9.

26. Stawarczyk B, Jordan P, Schmidlin PR, Roos M, Eichberger M, Gernet W. PEEK surface treatment effects on tensile bond strength to veneering resins. J Prosthet Dent 2014;112:1278-88.

27. Rzanny A, Göbel R, Fachet M. BIO HPP Summary of results for material tests. Quintessenz Zahntech MAG 2013;39(3):2-10.

28. Stawarczy B, Eichberger M, Uhrenbacher J, Wlmmer T, Edelhoff D, Schmidlin PR. Three-unit reinforced polyetheretherketone composite FDPs: Influence of fabrication method on load-bearing capacity and failure types. Dent Mater J 2015;34(1):7-12.

29. Shillingburg HT, Hobo S, Whitsett L. Fundamental of fixed prosthodontics. 3rd Edition, Quintessence, Chicago 1997; 119-37, 171-4.

30. Saridag S, Ozyesil AG, Pekkan G. Fracture strength and bending of all-ceramic and fiber-reinforced composites in inlay-retained fixed partial dentures. J Dent Sci 2012;7(2):159-64.

31. Hamza TA, Attia MA, El-Hossary MM, Mosleh IE, Shokry TE, Wee AG. Flexural strength of small connector designs of zirconia-based partial fixed dental prostheses. J Prosthet Dent 2016:1-6.

32. Creugers NH and Kanter RJ. Patient's satisfaction in two long term clinical studies on resin-bonded bridges. J Oral Rehab 2000;27:602-7.

33. Zalkind M, Hadani P, Hochman N. Resin-bonded fixed partial denture retention: A retrospective 13-year followup. J Oral Rehab 2003;30:971-7.

34. Daou EE. The Zirconia Ceramic: Strengths and Weaknesses. Open Dent J 2014;8:33-42.

35. Izgi AD, Kale E, Eskimez S. A prospective cohort study on cast-metal slot-retained resin-bonded fixed dental prostheses in single missing first molar cases: results after up to 7.5 years. J Adhes Dent 2013;15(1):73-84.

36. Sailer I, Feher A, Filser F, Gauckler LJ, Lüthy H, Hämmerle $\mathrm{CH}$. Five-year clinical results of zirconia frameworks for posterior fixed partial dentures. Int $\mathrm{J}$ Prosthodont 2007;20:383-8.

37. Fasbinder DJ. Materials for chair-side CAD/CAM restorations. Compend Contin Educ Dent 2010;31:702-9.

38. Oh WS and Anusavice K. Effect of connector design on the fracture resistance of all-ceramic fixed partial dentures. J Prosthet Dent 2002;87:536-42.

39. Hallmann L, Mehl A, Sereno N, Hammerle CH. The improvement of adhesive properties of PEEK through pretreatments. Appl Surf Sci 2012;258:7213-8.

40. Huang R, Wang XY, Gao XJ. Effects of Different Surface Treatments on Ceramic Repairs with Composite. Chin J Dent Res 2013;16(2).

41. Panah FG, Rezai SM, Ahmadian L. The influence of ceramic surface treatments on the micro-shear bond strength of composite resin to IPS Empress 2. J Prosthodont 2008;17:409-14.

42. Ayad MF, Fahmy NZ, Rosenstiel SF. Effect of surface treatment on roughness and bond strength of a heat-pressed ceramic. J Prosthet Dent 2008;99(2):123-30.

43. Braga RR, Meira JB, Boaro LC, Xavier TA. Adhesion to tooth structure: a critical review of "macro" test methods. Dent Mater 2010;26:38-49.

44. Tysowsky G. The science behind lithium disilicate: today's surprisingly versatile, esthetic and durable metal-free alternative. Oral Health J 2009;3:93-7.

45. Copponnex $\mathrm{T}$ and Carmine A. Re-evaluating thermoplastics. Eur Med Dev Manufac 2009;26-7.

46. Prochnow $\mathrm{C}$, Venturini $\mathrm{AB}$, Grasel R, Bottino $\mathrm{MC}$, Valandro LF. Effect of etching with distinct hydrofluoric acid concentrations on the flexural strength of a lithium disilicate-based glass ceramic. J Biomed Mater Res Part B 2017;105(4): 885-91.

47. Ali AO, Kelly JR, Zandparsa R. The influence of different convergence angles and resin cements on the retention of zirconia copings. J Prosthodont 2012;21(8):614-21.

48. Hayashi M, Miura M, Nishimura N, Takeshige F, Edisu S. Effects of cavity form and setting expansion of refractory dies on adaptability of fired ceramic inlays. Oper Dent 2000;25(1):33-9. 
49. Ozcan M, Breuklander MH, Vallitu PK. The effect of box preparation on the strength of glass fiber-reinforced composite inlay-retained fixed partial dentures. J Prosthet Dent 2005;93:337-45.

50. Vallittu PK and Sevelius C. Resin bonded glass fiberreinforced composite fixed partial denture. A clinical study. J Prothet Dent 2000;84:413-8.

51. Song HY, Yi Yj, Ch o LR.Effects of two preparation designs and pontic distance on bending and fracture strength of fiber-reinforced composite inlay fixed partial dentures. J Prosthet Dent 2003;90(4):347-53.

52. Mehmet A, Kilicarslan P, Kedici S. In vitro fracture resistance of posterior metal ceramic and all-ceramic inlay-retained resin-bonded partial dentures. J Prosthet Dent 2004;92:365-70.

53. Brunton PA, Cattell P, Burke FJ, Wilson NH. Fracture resistance of teeth restored with onlays of three contemporary tooth-colored resin-bonded restorative materials. J Prothet Dent 1999; 82:167-71.
54. Kurtz SM and Devine JN. PEEK biomaterials in trauma, orthopedic and spinal implants. Biomater J 2007;28: 4845-69.

55. Morrmann WH, Stawarczyk B, Ender A, Sener B, Attin T, Mehl A. Wear characteristics of current aesthetic dental restorative $\mathrm{CAD} / \mathrm{CAM}$ materials: Two-body wear, gloss retention, roughness and Martens hardness. J Mechanic Behav Biomed Mater 2013;20:113-25.

56. Quinn GD. Fractography of Ceramics and Glasses. Washington: Nation Instit of Standar and Tech 2007; 1-4.

57. Lakshmi RD. Influence of connector dimensions on the stress distribution of monolithic zirconia and lithiumdisilicate inlay retained fixed dental prostheses - A 3D finite element analysis. Tanta Dent J 2015;12(1):56-64.

58. El-khodary NA, Katamesh HA, Halim CH. In vitro Fracture Resistance and Marginal Accuracy of Zirconia Inlay-retained Fixed Partial Denture: A Systematic Review. Indian J Sci Technol 2016;9(8):1-7. 